\title{
Inhibitory Effect of the root of Polygala tenuifolia on Bradykinin and COX 2-Mediated Pain and Inflammatory Activity
}

\author{
Jung Jin Oh and Sung-Jin Kim* \\ Department of Pharmacology and Toxicology, School of Dentistry, Kyung Hee University, Seoul 130-701, Republic \\ of Korea
}

*For correspondence: Email: kimsj@khu.ac.kr; Tel: +82-2-961-0868; Fax: +82-2-957-5309.

Received: 17 July 2013

Revised accepted: 2 June 2013

\begin{abstract}
Purpose: To gain insight into the mechanisms of analgesic and anti-inflammatory activities of the root extract of Polygala tenuifolia.

Methods: Polygala tenuifolia was extracted with $70 \%$ methanol and tested for analgesic and antiinflammatory activities $(0.1,1,10$ and $100 \mathrm{mg} / \mathrm{kg})$ using the following models: acetic acid-induced writhing, rat paw edema, bradykinin inhibtion with rat ileum, and prostaglandin assay.

Results: Administration of the Polygala tenuifolia extract at $100 \mathrm{mg} / \mathrm{kg}$ dose produced significant analgesic effect on acetic acid-induced writhing (97\% inhibition) but its effect in the tail-flick test was not significant $(p<0.05)$. In addition, the extract exerted significant anti-inflammatory effect in the rat paw edema model (8 to $33 \%$ inhibition) at doses ranging from $0.1-100.0 \mathrm{mg} / \mathrm{kg}$ ). A significant inhibitory action (53\%) on the bradykinin-mediated contractions of rat ileum was also observed. Furthermore, the extract significantly $(p<0.05)$ inhibited the production of lipopolysaccharides-induced 6-keto-PGF $F_{1 \alpha}$ by $28 \%$ in macrophage cultures.

Conclusion: These results provide evidence that the Polygala tenuifolia root extract exerts analgesic and anti-inflammatory effects via its significant inhibitory effect on acetic acid writhing test, bradykinin-mediated actions as well as on 6-keto-PGF $F_{1 \alpha}$ induction.
\end{abstract}

Keywords: Polygalae radix, Bradylinin, Prostaglandin, COX-2, Inflammation, Analgesic

Tropical Journal of Pharmaceutical Research is indexed by Science Citation Index (SciSearch), Scopus, International Pharmaceutical Abstract, Chemical Abstracts, Embase, Index Copernicus, EBSCO, African Index Medicus, JournalSeek, Journal Citation Reports/Science Edition, Directory of Open Access Journals (DOAJ), African Journal Online, Bioline International, Open-J-Gate and Pharmacy Abstracts

\section{INTRODUCTION}

Medicinal plants are believed to be an important source of products with potential therapeutic effects on various diseases. Searching for new active extracts or components derived from various natural plants can be useful in the management of inflammation and pain [1]. Polygalae radix, the root of Polygala tenuifolia Willdenow (Polygalaceae), is a well-known traditional medicine used as an expectorant, tonic, tranquillizer, antipsychotic agent and functional diet for improving memory in China and Korea [2, 3]. It was widely used in the Chinese medicine prescription for 2000 years to treat insomnia, dream-disturbed sleep, forgetfulness and palpitation; promoting expectoration; used in cough; causing subsidence of swelling, used on boils and sores, swelling and pain [4].

Chemically, the Polygalae Radix contains a number of triterpene saponins named onjisaponins A, B, C, D, E, F and G [5]. Other constituents such as xanthone derivatives, 6hydro-xy-1,2,3,7-tetrameethoxy-xanthone, 
1,2,3,6,7-penta-methoxyxanthone, 3,4,5-trimethoxy-cinamic acid [6] and oligosaccharides tenuifolioses A-F [7] were isolated. Pharmacologically, it has been found that Polygalae Radix exerts a number of neuronal actions. It has been reported to exhibit neuroprotective and neuroregenerative effects [8], enhance cognitive functions [9], provide memory enhancement [10], ameliorate spatial cognition disorders [11], protect neuronal cells in toxin-induced Parkinson's disease [12] and exert anti-depressive action [13]. However, molecular mechanisms of Polygalae Radix that have been used traditionally should be fully investigated regarding its role in inflammation and pain. In the present study, we sought to evaluate the analgesic and anti-inflammatory effects of the Polygalae Radix extract and propose its mechanism of action.

\section{EXPERIMENTAL}

\section{Materials}

Polygalae radix was purchased from KyungDong Oriental Medicine Market, Seoul, Korea. They were authenticated by Professor Emeritus Chang-SooYok, Department of Oriental Pharmacy, Kyung Hee University, Seoul, Republic of Korea. A voucher specimen (no. 9802) was deposited at the herbarium of the Department of Pharmacology, School of Dentistry, Kyung Hee University. Organic solvent such as methanol, ether and $n$-butanol were molecular biology grade and purchased from Duksan Chemical Co, Seoul, Korea. Other materials used were purchased from Sigma Chemical Company, USA.

\section{Animals}

Male Sprague-Dawley rats $(200-250 \mathrm{~g})$ and male ICR mice $(15-25 \mathrm{~g})$ were purchased from Hanlim Experimental Animals Co. Korea. Animals were housed in a room with controlled temperature $\left(22 \pm 2{ }^{\circ} \mathrm{C}\right)$ under a $12 \mathrm{~h}$ light / dark cycle with free access to standard certified rodent diet and tap water. All experiments were performed according to the guidelines for the care and use of laboratory animals [ 14].

\section{Preparation of Plant Extracts}

Polygalae Radix $(250 \mathrm{~g})$ was cut into small pieces and extracted with $70 \%$ methanol (750 $\mathrm{ml}$ ) three times sequentially for $3 \mathrm{~h}$ on each occasion. The combined methanol extracts was concentrated in a rotary evaporator (Eyela N-N series) and dried in a freeze- dryer (FD5510 Freeze Dryer, Ilshin Lab, Republic of Korea).

\section{Acetic acid induced-writhing test}

Polygala tenuifloia extract or physiological saline was administered $(0.1,1,10,100 \mathrm{mg} / \mathrm{kg}, P O)$. After $10 \mathrm{~min}, 0.7 \%$ acetic acid $(0.1 \mathrm{ml} / \mathrm{kg}$, i.p.) was injected. Over the next $10 \mathrm{~min}$, the total number of writhings was measured [15].

\section{Tail-flick test}

Polygala tenuiflia extract or physiological saline was administered to rats $(0.1,1,10,100 \mathrm{mg} / \mathrm{kg}$, $\mathrm{PO})$. After $30 \mathrm{~min}$, rat tail-flick times were measured using Ugo-Basile tail-flick unit [16].

\section{Paw-edema test}

Anti-inflammatory activity was determined by carrageenin-induced paw edema test in rats [17]. Briefly, the rats was treated with extract or vehicle orally $(0.1,1,10,100 \mathrm{mg} / \mathrm{kg})$. After $1 \mathrm{~h}$, $0.1 \mathrm{ml}$ of $1 \%$ carrageenan was injected subplantarly into one of the hind paw and the contralateral paw was injected with $0.1 \mathrm{ml}$ saline as control. Edema measurements were made with Ugo-Basile Plethysmograph prior and 60 min after carrageenan injection.

\section{Evaluation of contractile responses of rat ileum}

Contractile responses of rat ileum were measured as essentially described by Schapoval et al. with slight modification [18]. The rats were scarificed by exposure to $\mathrm{CO}_{2}$ gas [19], and their ilea excised and mounted in an organ bath, oxygenated with $95 \% \mathrm{O}_{2}$ and $5 \%$ $\mathrm{CO}_{2}$. The organ bath was suspended at $37^{\circ} \mathrm{C}$ in Tyrode solution. Contractile responses were recorded isotonically with Grass ${ }^{\circledR}$ Low Level DC Amplifier (model 7P122P). After the equilibration period of $30 \mathrm{~min}$, concentration-response curves were generated by adding contractile agonist (bradykinin, $50 \mathrm{ng} / \mathrm{ml}$ ) to the organ bath. After washing the ileum and the baseline tension was restored, the extract $(40 \mu \mathrm{g} / \mathrm{ml}$,) was incubated in the organ bath for 15 min.,bradykinin was added and contractile responses recorded by MacLab 8E data acquisition system (AD Instruments)

\section{Isolation of mouse peritoneal macrophage and cultures}

Phosphate buffered saline $(\mathrm{pH} 7.4)(5 \mathrm{ml})$ was injected into ICR (Imprinting Control Region) mouse and peritoneal fluids were collected by using a needle. The peritoneal fluids were subjected to centrifuge to pellet macrophages. The resulting cell pellets were washed three 
times with PBS and resuspended with RPMI media at the concentration of $10^{6}$ cells $/ \mathrm{ml} .500$ $\mu \mathrm{M}$ of aspirin was added to the cells to irreversibly inhibit endogenous cyclooxygenase (COX) activity. The cell suspensions were applied to a 96-well dish (100 $\mu \mathrm{l} /$ well $)$ and cultured at $37{ }^{\circ} \mathrm{C}$ with $5 \% \mathrm{CO}_{2}$ atmosphere for 2 h. Thereafter, the cells were washed with PBS three times and used for experiments [1]

\section{COX-2 inhibition assay}

The cells were treated with $200 \mu \mathrm{l}$ of $3 \%$ FBSRPMI1640 media containing $10 \mu \mathrm{g} / \mathrm{ml}$ of LPS. The test materials were added to the wells at a final concentration of 1 or $10 \mu \mathrm{g} / \mathrm{ml}$ and incubated for 16 . Thereafter, the cell culture medium was collected and used to measure 6keto-PGF ${ }_{1 \alpha}$ by ELISA [1].

\section{Statistical analysis}

The values are expressed as mean \pm standard deviation (SD). The results were computed statistically (Graphpad Prism 5, Graphpad Software, Inc, La Jolla, CA, USA) using Student t-test or one-way analysis of variance. Post hoc testing was performed for intergroup comparisons using least significance test.

\section{RESULTS}

\section{Anti-noticeptive activity}

Anti-noticeptive activity was evaluated by acetic acid-induced writhing and tail-flick methods and the results are shown in Figs 1 and 2. Polygalae radix extract treatment significantly $(p<0.05)$ reduced the number of writhes by $29,39,68$ and $97 \%$ at doses of $0.1,1,10$ and $100 \mathrm{mg} / \mathrm{kg}$, respectively as compared to control. In the tailflick test, however, extract treatment produced little effect on latency time upon infra-red light exposure.

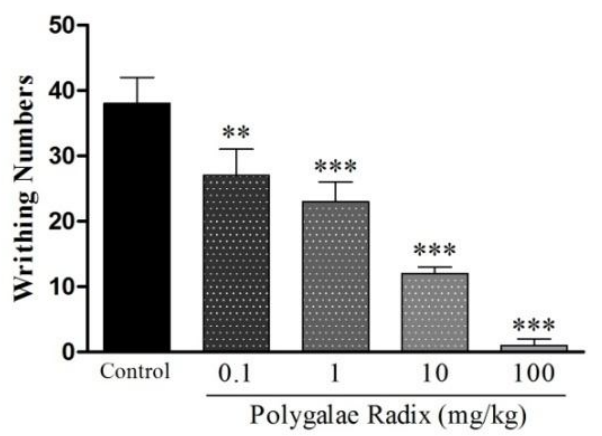

Fig 1: Effect of Polygalae radix extract on acetic acidinduced writhing. Data are expressed as mean \pm SD $(\mathrm{n}=5) ;{ }^{* *} p<0.01$ and ${ }^{* * *} p<0.001$ compared with control

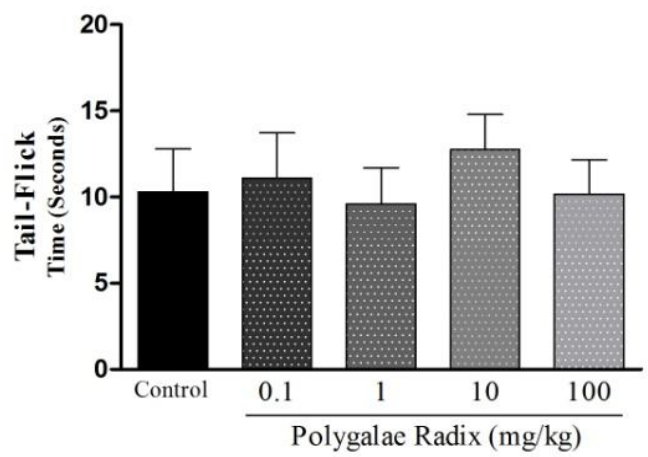

Fig 2: Effect of Polygalae radix extract on on tail flicks. Data are expressed as mean $\pm \operatorname{SD}(n=5)$. The effect of the extact was not significant at all doses tested $(p<0.01)$, compared with control

\section{Anti-inflammatory activity}

The results of the rat paw edema test are shown in Fig 3. The extract inhibited the carrageenininduced paw edema by $11,16,33$ and $8 \%$ at doses of $0.1,1,10$ and $100 \mathrm{mg} / \mathrm{kg}$, respectively, after $60 \mathrm{~min}$, compared to control. The effect was significant at only the first three doses..

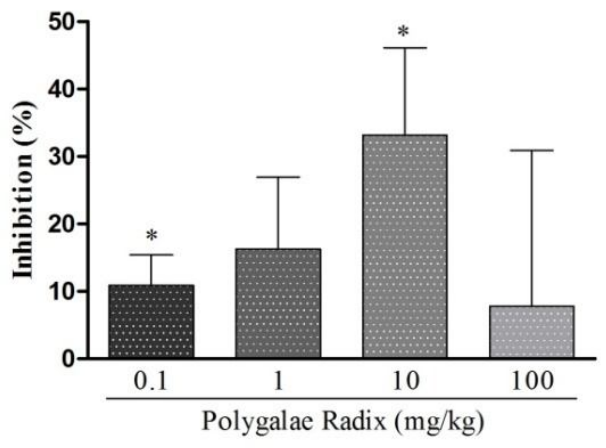

Fig. 3. Paw edema inhibition activity of Polygalae radix extract. Data are expressed as mean $\pm \mathrm{SD}(\mathrm{n}=4) ;{ }^{*} p<0.05$ compared with control.

\section{Effect of Polygalae radix extract on rat ileum contraction}

To gain insight into the mechanisms of analgesic and anti-inflammatory actions, the effect of Polygalae radix extract on the rat ileum contraction using bradykinin test was investigated. The extract $(40 \mu \mathrm{g} / \mathrm{ml})$ induced significant inhibition of bradykinin-induced contractions of rat ileum by $53 \%$ compared to control.

\section{Effect of Polygalae radix extract on COX-2 induction in macrophages}

The effect of $10 \mu \mathrm{g} / \mathrm{ml}$ of the extract on macrophages significantly inhibited LPS- 
mediated production of 6-keto-PGF ${ }_{1 \alpha}$ by $28 \%$ compared to control.

\section{DISCUSSION}

Polygala radix, the toot of Polygala tenuifolia, is a folk medicine widely applied to achieve amelioration of several neurodegenerative diseases such as Parkinson's disease, Alzheimer's disease and psychosis in Korea [20] In the present study, we evaluated the methanol extract of Polygalae radix for analgesic and antiinflammatory effects and also sought to gain an insight into the mechanism of its actions. There is evidence that the extract has remarkable analgesic and anti-inflammatory actions with inhibitory effects on bradykinin-mediated contraction of rat ileum as well as on the LPSinduced production of 6-keto-PGF ${ }_{1 \alpha}$ in mouse peritoneal macrophages.

Acetic acid induced writhing assay is used to detect both central and peripheral analgesia whereas tail-flick assay is more sensitive to centrally acting analgesics [21]. Our results indicate that the extract exerted significant dosedependent inhibitory effect with maximal effect observed at $100 \mathrm{mg} / \mathrm{kg}$ in acetic acid writhing assay but had no inhibitory effect in tail-flick test. In our previous report, we found that aspirin at $200 \mathrm{mg} / \mathrm{kg}$ has the ability to inhbit by $71 \%$ as compared to control in acetic acid writhing assay [22]. These results suggest that the Polygala tenuifolia extract is more potent than aspirin in terms of analgesic action. In terms of antiinflammation, it has been identified that ibuprofen $(50 \mathrm{mg} / \mathrm{kg})$ causes $63 \%$ inhibition of rat paw edema [22] whereas the Polygala tenuifolia extract inhibited rat paw edema by 33 $\%$ at $10 \mathrm{mg} / \mathrm{kg}$. Thus, it is reasonable to suggest that the extract has a strong inhibitory effect on peripheral noticeptive reaction rather than central action on pain transmission [23,24] In the carrageenan-induced rat paw edema test, the extract also exerted significant anti-inflammatory effect. These results indicate that the extract contains active components responsible for analgesic and anti-inflammatory actions.

Pain and inflammation are mediated by a number of chemical entities such as prostaglandins, histamine and bradykinin [25, 26]. In the present study, the extract inhibited prostaglandin synthesis and bradykinin-induced rat ileum contraction, thus strongly suggesting that it exerts anti-inflammatory action via inhibition of prostaglandin and bradykininmediated inflammation. It is reasonable to speculate that the Polygala tenuifolia extract exerts analgesic and anti-inflammatory activity by partly inhibiting bradykinin receptor-mediated reactions.

Cyclooxygenase (COX) is a key enzyme responsible for the production of prostaglandins and exists as isozymes including COX-1 and COX-2 [27]. COX-1 is a constitutively present enzyme in cells under physiological condition, whereas COX-2 is induced by some cytokines and mitogens which are endotoxins produced during inflammation [28]. COX-1 has cytoprotective action while COX-2 play important role in inflammation. LPS-induced synthesis of prostaglandins and thromboxanes in macrophages is known to be due to selective expression of COX-2. One of the major drawbacks of currently available NSAIDs (nonsteroidal anti-inflammatory drugs) such as aspirin is stomach irritation due to the inhibition of COX-1. The selective inhibitory effect on the COX-2 is essential for the development of a new generation of anti-inflammatory drugs. The present result suggests that the Polygala tenuifolia extract has the ability to inhibit the production of 6-keto-PGF ${ }_{1 \alpha}$, which may play an important role in its analgesic and antiinflammatory actions.

Thus, there is the interesting possibility that the extract could be used effectively to treat pain and inflammation without the side effect of stomach irritation. Since inflammatory reactions induce many reactive oxygen radicals, our results suggest that the extract could be beneficial in the protection of neurodegenerative diseases such as Parkinson's disease and Alzheimer's disease. With regard to the active components responsible for the extract's analgesic and anti-inflammatory activities, a thorough analytical investigation by employing activity-guided fractionation would be required. Interestingly, however, it has been proposed that sinapic acid is a probable active component of Polygalae radix responsible for antiinflammation, and hence its action could produce neuroprotection and memory improvement [20].

\section{CONCLUSION}

The present study strongly suggests that the methanol extract of Polygala tenuifolia exerts significant analgesic and anti-inflammatory effects. The extract can be used as functional food. It protects cells against oxidative stress and some inflammatory reactions, and therefore could be useful in the protection and treatment of some diseases caused by inflammation. 


\section{REFERENCES}

1. Kim SJ, Kim MS. Inhibitory Effects of Cimicifugae Rhizoma Extracts on Histamine, Bradykinin and COX-2 Mediated Inflammatory Actions. Phytother Res 2000; 14 : 596-600.

2. Huang KC. The Pharmacology of Chinese Herbs. Boca Raton, FL: CRC Press, Inc. 1993.

3. Zhang $H$, Han $T$, Zhang $L$, et al. Effects of tenuifolin extracted from radix polygalae on learning and memory: A behavioral and biochemical study on aged and amnesic mice. Phytomedicine 2008; 15:587-594.

4. Zhu Y-P. Chinese Materia Medica. Amsterdam, The Netherlands: Harwood Academic Publishers; 1998.

5. Sakuma S, Shoji J. Studies on the Constituents of the Root of Polygala tenuifolia WILLDENOW. I. Isolation of Saponins and the Structures of Onjisaponins $G$ and $F$. Chemical \& Pharmaceutical Bulletin 1981; 29: 2431-2441.

6. Ito $H$, Taniguchi $H$, Kita $T$ Matsuki $Y$, Tachikawa $E$, Fujita T. Xanthones and a cinnamic acid derivatives from Polygala tenuifolia. Phytochemistry 1977; 16: 1614-1616.

7. Miyase $T$, Iwata $Y$, Ueno $A$. Tenuifolioses a- $F$, Oligosaccharide Multi-Esters from the Roots of Polygala-Tenuifolia Willd. Chemical Pharmaceutical Bulletin 1991: 39: 3082-3084.

8. Park $\mathrm{CH}$, Choi SH, Koo JW, Seo JH, Kim HS, Jeong SJ, Suh $Y H$. Novel cognitive improving and neuroprotective activities of Polygala tenuifolia Willdenow extract, BT-11. J Neurosci Res 2002; 70: 484-492.

9. Shin $K Y$, Lee JY, Won $B Y$, Heo $C$, Kim HJ, Jang $D P$, Park CH, Kim S, Kim SH, Kim YB, Lee HG, Lee HS, Cho ZH, Suh YH. BT-11 is effective for enhancing cognitive functions in the elderly humans. Neuroscience Letters 2009; 465: 157159.

10. Li FQ, Cheng $X X$, Liang $X B$, Wang $X H$, Xue B, He $Q H$, Wang $X M$, Han JS. Neurotrophic and neuroprotective effects of tripchlorolide, an extract of Chinese herb Tripterygium wilfordii Hook F, on dopaminergic neurons. Exp Neurol 2003; 179: 2837.

11. Sun $X L$, Ito $H$, Masuoka $T$, Kamei $C$, Hatano T. Effect of Polygala tenuifolia root extract on scopolamineinduced impairment of rat spatial cognition in an eight-arm radial maze task. Biological \& Pharmaceutical Bulletin 2007; 30: 1727-1731.

12. Choi JG, Kim HG, Kim MC, Yang WM, Huh Y, Kim SY, Oh MS. Polygalae radix inhibits toxin-induced neuronal death in the Parkinson's disease models. J Ethnopharmacol 2011; 134: 414-21.

13. Liu $P, H u Y$, Guo DH, Wang DX, Tu HH, Ma L, Xie TT, Kong LY. Potential antidepressant properties of Radix Polygalae (Yuan Zhi). Phytomedicine 2010; 17: 794-799.

14. Guide for the care and use of laboratory animals, 8th edn. National Research Council of the National Acxademies. The National Academies Press, Washington, DC, USA
15. VanderWende, C, Margolin S.. Analgesic tests based upon experimentally induced acute abdominal pain in rats. Federation Proceedings 1956; 15: 494.16. D'Amour FE, Smith DL,. A method for determining loss of pain sensation. Journal of Pharmacology and Experimental Therapeutics 1941; 72: 74-79.

17. Winter CA, Risley EA, Nuss GW. Carrageenin-induced edema in hind paw of the rat as an assay for antiiflammatory drugs. Proc Soc Exp Biol Med 1962; 111: 544-547.

18. Schapoval EE, Vargas MR, Chaves CG, Bridi $R$, Zuanazzi JA, Henriques AT. Antiinflammatory and antinociceptive activities of extracts and isolated compounds from Stachytarpheta cayennensis. J Ethnopharmacol 1998; 60: 53-59.

19. Laboratory animals. An introduction for experimenters. Second edition. Editied by A.A. Tuffery. John Wiley and Sons. 1995

20. Karakida F, Ikeya Y, Tsunakawa M, Yamaguchi, $T$, Ikarashi Y, Takeda S, Aburada M. Cerebral protective and cognition-improving effects of sinapic acid in rodents. Biol Pharm Bull 2007; 30: 514-519.

21. Dewey WL, Harris LS, Howes JF, Nuite JA. The effect of various neurohumoral modulators on the activity of morphine and the narcotic antagonists in the tail-flick and phenylquinone tests. J Pharmacol Exp Ther 1970; 175: 435-442.22. Kim SJ, Zhang CG, Lim JT. Mechanism of anti-nociceptive effects of Asarum sieboldii Miq. Radix: potential role of bradykinin, histamine and opioid receptormediated pathways. J ethnopharmacol 2003; 88 : 5-9.23. Fukawa, K., Kawano, O., Hibi, M., Misaki, M., Ohba, S., Hatanaka, Y A method for evaluating analgesic agents in rats. Journal of Pharmacological Methods 4, 251-259.

24. Dewey, W.I., Harris, L.S., Howes, J.F., Nuite, J.A.The effect of various neurohumoral modulators on the activity of morphine and the narcotic antagonists in the tail-flick and the phenylquinone tests. J PharmacolExpTher 1970; 175: 435-442.

25. Lukacs NW, Strieter RM, Lincoln PM, Brownell E, Pullen DM, Schock $H$ J, Chensue SW, Taub DD, and Kunkel SL. Stem cell factor (c-kit ligand) influences eosinophil recruitment and histamine levels in allergic airway inflammation. J Immunol 1996; 156: 3945-3951.

26. Gao XP, Vishwanatha JK, Conlon JM, Olopade CO and Rubinstein I. Mechanisms of smokeless tobaccoinduced oral mucosa inflammation: role of bradykinin. J Immunol 1996; 157: 4624-4633.

27. Wallace, J.L. Distribution and expression of cyclooxygenase(COX) isoenzymes, their physiological roles, and the categorization of nonsteroidal anti-inflammatory drugs(NSAIDs). Am J Med 1999; 107: 11S-17S.

28. Mitchell JA, Akarasereenont $P$, Thiemermann C, Flower $R J$, and Vane JR. Selectivity of nonsteroidal antiinflammatory drugs as inhibitors of constitutive and inducible cyclooxygenase. Proc Natl Acad Sci U S A 1993; 90: 11693-11697. 